\title{
School Transitions as a Turning Point for Gang Status
}

\author{
Dena C. Carson \\ Indiana University Purdue University Indianapolis \\ Chris Melde \\ Michigan State University \\ Stephanie A. Wiley \\ Finn-Aage Esbensen \\ University of Missouri-St. Louis \\ Address correspondence to: \\ Dena C. Carson \\ School of Public and Environmental Affairs \\ 801 W. Michigan St; BS 3057 \\ Indianapolis, IN 46202 \\ 317-274-8707 \\ carsond@iupui.edu
}

\section{Disclaimer:}

This research was made possible, in part, by the support and participation of seven school districts, including the School District of Philadelphia. This project was supported by Award No. 2006-JV-FX-0011 and Award No. 2011-JP-FX-0101 from the National Institute of Justice, Office of Justice Programs, U.S. Department of Justice. The opinions, findings, and conclusions or recommendations expressed in this manuscript are those of the authors and do not necessarily reflect the views of the Department of Justice or of the seven participating school districts.

This is the author's manuscript of the article published in final edited form as:

Carson, D. C., Melde, C., Wiley, S. A., \& Esbensen, F. A. (2017). School transitions as a turning point for gang status. Journal of Crime and Justice, 40, 396-416. https://doi.org/10.1080/0735648X.2017.1329784 


\title{
School Transitions as a Turning Point for Gang Status
}

\begin{abstract}
The study of gangs corresponds well with life course perspectives of crime as the onset, persistence, and desistance from crime parallel the stages of gang membership. This literature commonly draws on turning points to explain the onset and desistance from criminal behavior, which are often synonymous with life transitions such as marriage, military duty, employmenteven gang membership itself. In this study we draw on life course perspectives to examine the impact of a specific life transition that is common during adolescence, school transitions, on a youth's gang status as well as variables associated with a turning point in the life course. Specifically, we focus on two competing relationships that school mobility can serve as the impetus for joining a gang, or alternatively, act as a "hook for change" and facilitate gang leaving. We use a mixed-methods approach by first drawing on qualitative data that examined desisted gang members and their interpretation of their school transition experiences. Second, consistent with a grounded theory approach, we examined these relationships quantitatively using a panel study of youth followed over a five year period.
\end{abstract}

Keywords: gang desistance; school transitions; life course theory 


\section{Introduction}

Gang researchers have often drawn upon life course perspectives to understand the trajectories of gang careers. This is a natural application as the joining, duration, and exit from gang life correspond with the onset, persistence, and desistance stages of the criminal career trajectory. Similarly, those who join a gang do so at varying ages, remain involved for different lengths of time, and have unique exit processes. These trajectories can be impacted or altered by turning points, which according to Sampson and Laub (2005), include life events such as marriage, military duty, and employment. The effect of other life events, such as school mobility, is less clear. Changing schools, either through the normative transition to high school or otherwise, may be salient transition points for youth because they occur during a period when youth are cultivating friendships and shaping their sense of self (Hagan, MacMillan, and Wheaton 1996; Langenkamp 2016; Meeus 2011).

School transitions vary in the impact that they have on youth. Transitioning or transferring to a new school causes disruption as youth must familiarize themselves with a new_and at times, very different—social and physical environment. This disruption can cause uncertainty, confusion, and insecurity. At the same time, enrollment in a new school provides youth with opportunities for changes in peer groups, new social and extracurricular activities, and alteration of social identity. Research that has examined the consequences of school transitions has been mixed, regardless of the type of transition (i.e., normative or non-normative). The normative transition from middle to high school has been found to have both negative and positive impacts including decreased self-esteem (Blyth, Simmons, and Carlton-Ford 1983) and lower test scores (Roeser, Eccles, and Freedman-Doan 1999), but also improved attendance (Isakson and Jarvis 1999). The impact of non-normative school transitions (i.e., changes due to 
residential moves or mid-year transfers) has also been mixed, with research demonstrating improved school outcomes such as test scores and greater commitment to school (Leventhal and Brooks-Gunn 2004; Ludwig, Ladd, and Duncan 2001) as well as negative impacts such as increased criminal offending (Gasper, DeLuca, and Estacion 2010), reduced commitment to school (Pribesh and Downey 1999), and increased risk for drop out (Rumberger and Larson 1998). Additionally, school transfers are associated with a reduction in the size of a youth's peer network (Siennick, Widdowson, and Ragan 2016; South and Haynie 2004). The current study examines the impact of school mobility on joining or leaving a youth gang, a particular type of peer network.

We draw on the life course perspective as well as previous research on the impact of school mobility to examine whether school transitions impact gang membership status in a manner consistent with a turning point framework. School transitions are a point of concern for practitioners as nearly all school age youth experience at least one change in school context, and approximately 20 to 25 percent of youth experience a non-normative school change outside the transition from, for example, middle to high school (Gasper, DeLuca, and Estacion 2010; Rumberger and Larson 1998). Given their regularity, it is important to understand how these transitions impact a youth's life course in order to help school officials reduce potential negative consequences associated with changing schools. To this end, we draw on works from Melde and Esbensen $(2011 ; 2014)$ and explore the ability of school transitions to act as a turning point in the life course. The variables used by Melde and Esbensen $(2011 ; 2014)$ represent the processes associated with a turning point in the life course, as described by Sampson and Laub (2005). Sampson and Laub (2005) suggested that changes in these mechanisms are particularly responsible for shaping criminal trajectories across the life course, and can be impacted by 
salient life events, such as changes in romantic relationships, employment status, and military service in early adulthood. Melde and Esbsensen (2011; 2014) demonstrated that joining a gang, and to a lesser extent leaving a gang, produced substantial changes in these factors, and helped to explain concomitant changes in involvement in delinquent and criminal behavior. There is reason to believe that transitioning schools is also capable of impacting these mechanisms, as well as resulting in changes to gang membership status. Research on school transitions, however, has not yet suggested this event is a systematic turning point in the life course, as there is evidence that changes in schools can be either a positive or negative event for youth, depending upon how youth respond to the change, and thus is not necessarily criminogenic.

Our first goal in this paper is to examine the extent to which school transitions have a direct impact on gang status. Given that school transitions can produce positive and negative effects on youth, depending on how they respond to the move, our second goal is to examine the impact of school transitions on the correlates of gang membership that have been associated with a turning point in the life course. By examining the direct impact of school transitions on these variables we advance the literature on school transitions as well as determine how changing schools can impact the relationship between gang joining/leaving and the variables outlined by Melde and Esbensen (2011; 2014). Our final goal, then, is to assess the extent to which the interaction between school transitions and gang joining or leaving affect these correlates of gang membership. In other words, school transitions, when coupled with gang joining or leaving, may accelerate or slow changes in these correlates of gang membership. We examine these research questions through a mixed-methods lens by first examining qualitative data on the ways in which desisted gang members interpret their school transition experiences. Consistent with a grounded 
theory approach, we then look at the more general quantitative relationships found in a panel study of youth.

\section{The Potential Impact of School Transitions on Gang Status}

Gang research has drawn extensively on a life course framework to understand the impact of gang joining (i.e., gang membership as a turning point) as well as to understand leaving the gang (i.e., the desistance process). Research on the age-graded nature of gang membership finds that onset occurs in the early teens, peaks at the age of 14 to 15 , and declines thereafter (Craig et al. 2002; Esbensen and Huizinga 1993; Huff 1996, 1998; Pyrooz 2014). As Thornberry and colleagues (2003) argued, gang membership can be thought of as a trajectory and as with any life course trajectory, onset and desistance can be altered by turning points in the life course. According to Sampson and Laub (2005), turning points typically change the life course by 1) allowing for "knifing off" from the past; 2) creating new relationships and altering social supports; 3) changing routine activities; and 4) providing opportunities for identity transformation.

Turning points are often understood in the gang literature in terms of push and pull factors associated with gang leaving and gang joining. In terms of leaving the gang, pull factors away from the gang are most commonly associated with turning points in a life course because they present options that are more attractive than gang membership. Pulls away from the gang can come in the form of life transitions such as employment, entering into a romantic relationship, parenthood and, specific to our interests, school mobility (Carson and Esbensen 2016; Carson, Peterson, and Esbensen 2013; Decker and Lauritsen 2002; Decker and Pyrooz 2011). Push factors are internal to the gang member and may result in making the gang environment seem less appealing such as disillusionment with gang life or maturation (Carson 
and Esbensen 2016; Carson, Peterson, and Esbensen 2013; Decker and Lauritsen 2002; Decker, Pyrooz, and Moule Jr. 2014; Pyrooz and Decker 2011). These push motivations are commonly associated with developmental theories because of an associated identity transformation. While school mobility may be classified as a turning point for gang youth, it can also act as a hook for change that facilitates the process through which youth pull themselves out of a gang as part of a process of identity transformation (Giordano, Schroeder, and Cernkovich 2007). In the case of gang joining, pull factors make the gang look attractive to an outsider and may include access to money or members of the opposite sex, ability to gain respect or status, or simply to fit in better (Decker and Curry 2000; Decker and Van Winkle 1996; Esbensen and Winfree 2013; Thornberry et al. 2003). Pushes into the gang are those mechanisms that compel a youth to join, which is commonly the case when youth seek protection from victimization (Decker and Van Winkle 1996; Esbensen and Winfree 2013; Thornberry et al. 2003). It is possible that school transitions generate the push and pull factors that increase the likelihood of gang joining.

School transitions, even when youth are forewarned, may abruptly "knife off" youth from their previous relationships. This effect is even more likely if individuals find themselves in a small cohort of youth transitioning to the new school or if youth experience a school transfer outside of the normative school transition. School mobility may immediately lead to gang desistance by cutting off communication with the gang, especially if the move represents upward mobility to a better neighborhood or school. By abruptly knifing off from former gang ties, the school transition also offers a fresh start and opportunity for identity transformation. That is, the school transition can serve as a mechanism to shed the "gang member" label, which may have been applied by community members, classmates, and/or teachers (Decker and Van Winkle 1996). In particular, the process of identity transformation and changes in peer groups and 
activities are likely reciprocal: as youth become more self-reflective and aware of their individuality, the social structure of their peer groups change, and youth in turn develop more positive self-conceptions, further altering identity (Kinney 1993). In addition to these processes, the development of social skills such as peer resistance or refusal skills either over time or via prevention programming can aid in gang desistance and keep youth from joining new gangs at their new schools (i.e., Esbensen et al. 2013). These developments are consistent with Giordano and colleagues' (2007; p. 1607) discussion of desistance processes more generally: “offenders have much to learn from others whose behavior presents a strong contrast to their own criminal lifestyles, and this contrast poses a distinct developmental challenge that maximizes opportunities for further growth and development.” Therefore, if youth are successful at breaking away from their gang and antisocial peers more generally and surround themselves with more prosocial others it should affect cognitive and emotional (e.g., anger identity) processes associated with reduced deviant behavior.

Social capital, or the social ties that provide information and resources can increase the status of youth (Coleman 1990; Hagan, MacMillan, and Wheaton 1996). Peers are a particularly salient form of social capital during adolescence, as youth begin to spend increasingly more time with peers and tend to rely on them as a source of social standing, personal identity, and values (Fuligni et al. 2001; Smetana, Campione-Barr, and Metzger 2006). School mobility (whether normative or non-normative) affects social capital because it can rupture these established friendships (Siennick, Widdowson, and Ragan 2016; Weller 2007). Because the gang is a source of social capital (Moule Jr., Decker, and Pyrooz 2013), school transitions may facilitate the desistance process by removing that source of social capital. But along with removing former sources of social capital, youth typically have a larger pool of peers and wider variety of 
extracurricular activities when they move to larger schools, such as during the transition from middle to high school. This increased variety provides youth with the opportunity to find friends who are more compatible or have similar interests (Weller 2007). By presenting gang youth with the ability to foster new relationships, moving to a new school can promote disengagement from the gang (Carson and Esbensen 2016) as well as desistance from crime (Warr 1998, 2002). ${ }^{1}$ In fact, several studies point to a positive impact of school transitions, whether normative or otherwise, on peer relations, finding that school transitions are associated with increased social support and fewer negative peer relations (Barber and Olsen 2004; Roeser, Eccles, and Freedman-Doan 1999; Weiss and Bearman 2007).

Until this point, we have discussed the ways in which school transitions may facilitate a change in gang status by cutting off ties from the gang, introducing youth to prosocial activities and peers, and generating identity transformations that facilitate gang desistance. Alternatively, school transitions have the potential to introduce youth to a social milieu that encourages gang membership. One of the greatest concerns when transitioning to a new school is the attenuation of bonds with peers, schools, counselors, administrators, and even parents. Because these forms of social capital serve as key sources of supervision as well as social control in the lives of mobile youth (Pribesh and Downey 1999; Siennick, Widdowson, and Ragan 2016), disruptions in social capital could lead to gang joining through several processes. Vigil (1993) observed that the lack of social control is especially problematic during the transition from elementary to middle school and, in turn, facilitated gang joining in his sample. Vigil's (1993) findings are corroborated both by work that finds that gang membership increases from $6^{\text {th }}$ to $7^{\text {th }}$ grade

\footnotetext{
${ }^{1}$ We note that dropping out of school can also facilitate the desistance process (Brunson and Miller 2009; Pyrooz, Decker, and Webb 2014; Pyrooz, Fox, and Decker 2010). However, because our quantitative sample does not include youth who dropped out of school, we cannot empirically examine this effect.
} 
(Gottfredson and Gottfredson 2001) and research on the age-graded incidence of gang status (Craig et al. 2002; Esbensen and Huizinga 1993; Pyrooz 2014).

Gangs can serve as a source of social capital and afford youth with a sense of belonging as well as status and respect (Alleyne and Wood 2010; McGloin and Collins 2015; Woo et al. 2015). In this way, the need to gain respect or increase status acts as a pull mechanism into the gang because it makes the gang an attractive option for quickly building social capital, particularly if youth experience difficulty gaining entrée into prosocial groups (South and Haynie 2004). This notion is upheld in the gang joining literature, as 18 to 60 percent of gang members report they joined the gang to attain status or respect (Decker and Curry 2000; Decker and Van Winkle 1996; Esbensen and Winfree 2013). Along with changes in peer groups, some research suggests that participation in extracurricular activities declines following school transitions, particularly in the transition from middle to high school (Barber and Olsen 2004; Blyth, Simmons, and Carlton-Ford 1983; Seidman et al. 1994). These changes in routine activities, combined with the increased autonomy and decreased parental involvement that comes with normative developmental progression as youth transition between levels of school, could result in youth spending more time with or becoming more committed to delinquent peers and deviant groups, such as gangs.

In addition to decreased parental guardianship, the loss of relationships with teachers and peers that comes with school transitions can also result in decreased social capital that negatively affects school-related outcomes (Pribesh and Downey 1999). Research on normative school transitions, for instance, indicates that academic achievement, school engagement, and support from teachers decrease after youth transition to a new school (for review, see Benner 2011 or Symonds and Galton 2014). One common explanation for these declines is that the academic 
rigor and expectations for students increase along the elementary to high school continuum (Eccles, Lord, and Midgley 1991; Eccles and Midgley 1988). Students are often expected to perform at higher levels, but when they fail they tend to withdraw from and become less committed to school. Moreover, school transitions - regardless of timing - involve unfamiliar environments, which can cause anxiety and uncertainty and account for declines in youth's school involvement and academic achievement (Benner and Graham 2009; Isakson and Jarvis 1999).

The unfamiliar school environment, coupled with the lack of guardianship that former classmates and teachers offered, can create a sense of insecurity among youth who change schools. Indeed, bullying is a common student concern when transitioning to middle or high school and is often realized after youth transition to a new school (see Symonds and Galton 2014, for review). Moreover, when mobile youth are classified as "easy targets" and feel they are vulnerable to victimization (Carson, Esbensen, and Taylor 2013), they may see a gang as their best option for garnering protection (Decker and Van Winkle 1996; Esbensen and Peterson Lynskey 2001; Esbensen and Winfree 2013; Thornberry et al. 2003). ${ }^{2}$ Approximately 54 percent of gang youth in an eleven city study reported that the gang's ability to provide protection served as a central motivation for joining (Esbensen and Peterson Lynskey 2001). Other research supports the idea that youth who transition schools feel the need for increased protection: those who transitioned to a new school between $8^{\text {th }}$ and $9^{\text {th }}$ grade were more likely than those who did not transition to bring a weapon to school (Weiss and Bearman 2007).

With respect to gang joining, however, all of these potential processes must be tempered by the realization that gangs are active in the selection process (Pyrooz and Densley 2016). That

\footnotetext{
${ }^{2}$ Joining a gang for protection frequently leads to the opposite effect, as gang youth are more likely to be victimized than nongang youth (Melde, Taylor, and Esbensen 2009; Taylor et al. 2008; Taylor et al. 2007).
} 
is, even if youth who transition to a new school desire the social and personal benefits (e.g., protection, social capital) afforded through gang membership, gangs in the new school environment may be leery of accepting a new student into their group given the risks this may have for their "brand." If gangs were simply to allow any and all willing individuals into their ranks, they run the risk of including individuals that do not personify the attributes and messages their gang wishes to convey in their environment, which routinely includes the ability to intimidate outside groups and persons, and back up this message through violence when necessary (Decker 1996). In this way, school transitions may lead to a reduction in the probability of gang membership whether or not the individual seeks to desist from gang membership or purposively change their social identity. If this is the case, one might find the likelihood of gang membership diminishes, but the associated effect on social-psychological processes is null; only the opportunity for gang membership has changed.

The transition to a new school, therefore, appears to come with both challenges and opportunities for positive youth development. Changes in both the social and physical environment can be stressful for youth, and has been shown to increase anxiety levels while at the same time disrupting ties with potential sources of social support, such as teachers, parents, and friends. On the other hand, transitioning to a new school can be conceptualized as a "hook for change," whereby youth can use this opportunity to structure their social lives in a way that allows for and facilitates identity transformations, consistent with Giordano and colleagues (2007) neo-Meadian perspective on changes in the life course. Importantly, this perspective suggests school transitions may be particularly beneficial for gang involved youth who wish to shed their deviant identity in so much as it produces a "contrast effect in connection with roletaking and social influence processes" (Giordano, Schroeder, and Cernkovich 2007; p. 1607). 
The current study draws on life course perspectives (Giordano, Schroeder, and Cernkovich 2007; Sampson and Laub 2005), as well as research on the impact of both normative and nonnormative school transitions to examine the utility of school mobility as a turning point for gang trajectories. Our research goals are threefold: 1) explore the direct impact of school mobility on gang status; 2) examine the impact of school mobility on correlates of gang membership considered to be consistent with a turning points framework [see figure 1] (see Melde and Esbensen 2011; 2014); and 3) assess whether changes in gang status that are simultaneous to school transitions produce differential effects on these variables, consistent with Giordano, Schroeder, and Cernkovich's (2007) discussion of contrast effects.

\section{Methods}

The current study uses a mixed-methods approach to examine the link between school mobility and gang status. In the following section, we outline our qualitative and quantitative methods and analysis plans. The quantitative data are drawn from the National Evaluation of the G.R.E.A.T. (Gang Resistance Education and Training) Program. The G.R.E.A.T. program is a school-based gang prevention program taught by law enforcement officers targeting middle school youth (i.e., 11 and 12 year olds). Data collection took place between 2006 and 2012 in seven cities: Albuquerque, New Mexico; Chicago, Illinois; Greeley, Colorado; Nashville, Tennessee; Philadelphia, Pennsylvania; Portland, Oregon; and a city in the Dallas/Fort Worth, Texas area. These cities were selected for the evaluation based on the existence of an established G.R.E.A.T. program, geographic and demographic diversity, and presence of gang activity (see Esbensen et al. 2013, for more detail about the evaluation design). While all students $(n=4,905)$ in these classrooms could participate in the evaluation, a thorough active parental consent process resulted in 78 percent of students being given permission by a parent or guardian to participate in 
the evaluation $(n=3,820)$. This active parental consent rate is exceptional as 89 percent $(n=$ 4,372) returned consent forms (see Esbensen et al. 2008 for a detailed description of procedures and factors related to active consent). In 2006, students completed pre-test and post-test (waves 1 and 2) self-report surveys with completion rates of 98.3 and 94.6 percent, respectively. ${ }^{3}$ The sample also completed four annual follow-up surveys (Waves 3, 4, 5, and 6), with participation rates of $87,83,75$, and 73 percent, respectively.

The qualitative data come from a subsample of the G.R.E.A.T. evaluation. Those youth who self-reported gang membership (i.e., “Are you now in a gang?”) (n=512) or who met the Eurogang definition ${ }^{4}(n=697)$ in one or more waves of the G.R.E.A.T. evaluation were eligible to participate in the second study. The study design called for a comparison of stable (selfnominated involvement in two or more consecutive waves $-\mathrm{n}=156$ ) and transient (self-reported involvement in at least one, non-consecutive, wave $-\mathrm{n}=356$ ) gang youth. The sampling strategy relied upon a purposive over-sampling of stable youth $(\mathrm{n}=131)$ and a random sampling of both transient gang youth $(n=198)$ and youth who fit the Eurogang definition $(n=97) .{ }^{5}$ This strategy resulted in a sampling frame of 426 youth who either self-nominated as a gang member or met the Eurogang definition. While few parents and/or youth declined to participate (5.3\%), a number of selected youth were not interviewed because they had moved (27.7\%), because researchers failed to find the youth at home in spite of repeated visits to the address (20.2\%), and for other reasons such as being non-responsive to the inquires to participate (4.2\%). The final

\footnotetext{
${ }^{3}$ Due to an under-representation of African American youth in Chicago schools obtained in a 2006 sampling effort, two additional schools were included in the evaluation, beginning during the 2007-2008 school year (Esbensen et al. 2013).

${ }^{4}$ The Eurogang Program of Research defines a street gang as "any durable, street-oriented youth group whose involvement in illegal activity is part of its group identity." For more information on the Eurogang and this definition please see Maxson and Esbensen (2016).

${ }^{5}$ It is important to note that the sampling strategy of the original study design stipulated that youth were not included in the pool of Eurogang youth if they self-nominated as a gang member at any wave of the G.R.E.A.T. evaluation.
} 
sample size consisted of 180 youth. It is important to note that given the retrospective nature of the interviews, in some instances, gang membership was reported as far back as 2006 (the qualitative interviews were conducted in the summer of 2012). Given this timeframe, some youth did not acknowledge their gang status during the interviews $(n=53) .{ }^{6}$ The project staff reviewed, discussed, and confirmed the status of the remaining 127 youth. ${ }^{7}$ The focus of the study was on gang desistance and, therefore, a number of the youth were no longer gang involved ( $\mathrm{n}=107)$. In-depth semi-structured qualitative interviews were conducted face-to-face, in confidential settings, by trained interviewers with these youth in all seven cities included in the G.R.E.A.T. evaluation.

\section{Quantitative variables and measurement}

The quantitative variables are consistent with what Sampson and Laub describe as the mechanisms of a turning point, as highlighted by Melde and Esbensen $(2011 ; 2014)$ and are also relevant outcomes of interest within the school transitions literature [see figure 1].

\section{Control variables}

Demographic (i.e., sex, race/ethnicity, age), school, and programmatic controls were included in all multivariate analyses. Biological sex was coded dichotomously, with male equal to one, and females serving as the reference group. The sample had slightly more female (52\%) than male respondents (see table 1), although 56 percent of the self-reported gang youth were male, which is comparable to other school-based studies (e.g., Esbensen, Osgood et al. 2001; Melde and Esbensen 2011; Pedersen and Lindstadt 2012; Weerman 2012). Race/ethnicity was controlled

\footnotetext{
${ }^{6}$ While reasons for reinterpretation vary, statistical analysis reveals no differences across youth who retrospectively reported gang membership and those who did not on a variety of variables ranging from demographics to attitudes and behaviors.

${ }^{7}$ Three to four project members read the interview transcripts and formed consensus opinions on the gang status of each youth.
} 
through a series of dummy variables, including black/African American, Hispanic/Latino, and a variable for "other" race/ethnicity, with non-Hispanic/white respondents serving as the reference group. Hispanic/Latino (38\%) respondents were the largest ethnic group in the study, followed by 25 percent of the sample who reported being non-Hispanic/white, 21 percent who reported being black/African-American, and 16 percent of respondents who reported another race/ethnicity.

Controlling for age was particularly important given the aforementioned age and gradelevel differences in gang status (Craig et al. 2002; Esbensen and Huizinga 1993; Gottfredson and Gottfredson 2001; Huff 1996, 1998; Pyrooz 2014). Age and age squared, measured at baseline, were included in all multivariate models examining the factors associated with a turning point. Over the study period students ranged in age from 9 to 18 although the majority of the students, who began the study in sixth grade at age $11(60 \%)$ or $12(29 \%)$, were between 11 and 15 years of age over the course of the study. Age was centered at 12 in the multivariate models. The school-level socioeconomic status for students' original school of enrollment was controlled through the inclusion of a variable measuring the percent of students eligible for free or reduced lunch in the school, which ranged from 23 percent to 96 percent of students across schools (mean $=.64$, standard deviation $=.23$ ). This variable was standardized through a z-score transformation before it was included in all multivariate models. Finally, a control for involvement in the G.R.E.A.T. program was included in all models (G.R.E.A.T. participant $=1$; Control $=0$ ), as was a variable indicating whether or not respondents transitioned to high school at wave 4 or wave 5 of survey administration (wave $4=1$, wave $5=0$ ).

\section{Gang membership}


Gang membership was measured via self-nomination by asking respondents "Are you now in a gang?," at each wave of data collection, with non-gang members coded " 0 " and gang members coded "1." While there remains a debate on the best way to measure gang membership, prior work has found that self-report is a valid indicator of involvement in a gang (Decker et al. 2014; Esbensen, Winfree, et al. 2001; Thornberry et al. 2003). With respect to gang membership, a total of 512 respondents reported being a gang member on at least one occasion during the study. Of those 512 gang members, 288 individuals provided uninterrupted data between the time they had not yet reported gang membership and when they self-identified as a gang member, or what we refer to as gang joining. On the other hand, 325 respondents provided uninterrupted data between the time of their self-reported gang membership and when they ceased to identify as a gang member, or what we label gang desistance. Together, these measures were used to determine whether there was a significant association between school transitions and changes in gang membership status to determine if school transitions were systematically associated with gang membership.

\section{School Transitions}

School transitions data were documented through logs maintained by program evaluators from the original project. Three dichotomous variables were created to account for school transitions, each coded 0 for no, and 1 for yes. An overall school transition variable was created to identify a school transition of any kind, whether normative or non-normative. Alternatively, a variable that identified normative school transitions was created (i.e., normative school transition), which identified the transition from middle school to high school in each of the participating sites. Finally, a variable was created to identify school transitions that occurred when they were not an expected part of the normative school progression through grades (i.e., middle school/junior high 
to high school), labeled Non-normative Transition. That is, these school transitions were from one middle school to another middle school, or from one high school to another high school. Peer group size

Peer group size was measured through an ordinal indicator of the number of friends the respondent reported having. In particular, after respondents were asked whether or not they have a group of friends, they were asked "about how many people, other than you, belong to this group?" Responses ranged from 1 to 7, with 1 equal to 1, 2 equal to 2 to 5,3 equal to 6 to 10,4 equal to 11 to 20,5 equal to $21-50,6$ equal to 51 to 100 , and 7 equal to more than 100 . Those who reported not having a peer group were coded as 0 .

\section{Prosocial peers}

Our measure of prosocial peers represents the proportion of the respondent's peer group that was considered prosocial based on their responses to a four-item scale. To introduce these items, students were asked "During the last year, how many of your current friends have done the following?" Then each of the following items were read to the students: "Have been thought of as good students," "Have gotten along well with teachers and adults at school," "Have been generally honest and told the truth," and "Almost always obeyed school rules." Responses were based on a five-point scale ranging from "None of them" to "All of them" $(\alpha=.83) .{ }^{8}$

\section{Peer delinquency}

Peer delinquency was measured by a construct that identified the proportion of the respondent's peers who engaged in seven different delinquent behaviors, including acts that ranged in severity from skipping school without an excuse to attacking someone with a weapon. Responses were

\footnotetext{
${ }^{8}$ All alpha scores are calculated at wave 1.
} 
coded on a five-point scale with one equal to "none of them" and five equal to "all of them" $(\alpha=$ .89).

\section{School commitment}

School commitment was measured through student responses to seven statements about school activities, including "I try hard in school," "In general, I like school," and "Grades are very important to me." Responses were based on a five-point Likert scale ranging from "strongly disagree" to "strongly agree" $(\alpha=.77)$.

\section{Violence neutralization}

Consistent with Sykes and Matza's (1957) techniques of neutralization, three statements concerning the appropriateness of violence in certain situations were presented to respondents, including: "It's okay to beat up someone if they hit you first," "It's okay to beat up someone if you have to stand up for or protect your rights," and "It's okay to beat up someone if they are threatening to hurt your friends or family." Answers were recorded using a five-point Likert scale $(\alpha=.88)$.

\section{Parental monitoring}

Four items were presented to respondents concerning how closely their parents monitored their behavior. Statements included items such as "My parents know who I am with if I am not at home," and "My parents know where I am when I am not at home or at school." These items were measured on a five-point Likert scale $(\alpha=.81)$.

\section{Negative peer commitment}

Commitment to deviant peers was assessed using three items measured on a five-point scale ranging from "not at all likely" to "very likely." The three questions included in the scale $(\alpha=$ 
.86) asked respondents "If your group of friends was getting you into trouble (at home/ at school/ with the police), how likely is it that you would still hang out with them?"

\section{Unstructured socializing}

To measure unstructured socializing, we created a three item additive index based on whether youth engaged in particular activities. Respondents indicated whether or not they "spend a lot of time together in public places like the park, the street, shopping area, or the neighborhood," "ever spend time hanging around with your current friends not doing anything in particular where no adults are present," or "ever spend time getting together with your current friends where drugs and alcohol are available.” The index ranges from zero to three.

\section{Guilt}

To measure respondents' anticipated feelings of guilt related to participation in delinquent activities, respondents were asked, "How guilty or how badly would you feel if you...," engaged in seven different acts that ranged in severity from "stole something worth less than $\$ 50$ " to "attacked someone with a weapon." Responses were based on a three point scale ranging from "not very guilty/badly" to "very guilty/badly" $(\alpha=.93)$.

\section{Anger identity}

We utilized the four-item scale developed by Grasmick and colleagues (1993) to measure the anger/temper component of the self-control construct as our indicator of anger identity. This is consistent with Giordano, Schroeder, and Cernkovich's (2007) concept, which has been found to be a robust correlate of violent behavior across the life course. Items included statements such as "I lose my temper pretty easily," and "When I'm really angry, other people better stay away from me." Responses were coded on a five-point Likert scale $(\alpha=.83)$.

\section{Qualitative and Quantitative analytic plan}


In keeping with a grounded theory approach, we began our analyses with examination of the qualitative data and then moved on to a larger, more general, quantitative sample. The qualitative portion of these analyses utilized in-depth interviews with desisted gang youth to identify themes surrounding the desistance motivation associated with mobility. The narratives were examined using line-by-line open and focused coding, which allowed for the identification of themes using a modified grounded theory approach (Charmaz 2006; Glaser and Strauss 1967). The results presented below represent the most common patterns that emerged around mobility as a motivation for gang disengagement and, consistent with grounded theory, serve as the basis for our quantitative analyses. While the qualitative results are not generalizable to the population or completely representative of our sample, they provide insight into the experiences of these desisted youth as well as the meanings they assigned to their unique desistance processes.

Using the quantitative data, we assess the impact of school transitions on gang membership status and the cognitive, affective, and behavioral components characteristic of a turning point in the life course (Graber and Brooks-Dunn 1996; Rutter 1996; Sampson and Laub 2005), using two strategies. First, we use panel fixed effects logit regression to estimate the impact of school transitions (both normative transitions and non-normative transitions) on the probability of gang onset, persistence, and desistance. We restricted these models to only those cases where respondents reported going through these stages of gang membership at some point during the study $(\mathrm{n}=288,512,325)$ given the absence of variation in this outcome across schools ${ }^{9}$. An advantage in panel fixed effects models is that they control for all time-stable characteristics of the persons under study, and thus help to isolate the effect of a school transition on gang status transitions (Allison 2009).

\footnotetext{
${ }^{9}$ There was non-significant variation at level 3 (i.e., the school level) in three level HLM models when the outcome was restricted to those experiencing some variation in gang status.
} 
Second, we use three-level discontinuous regression models (Singer and Willett 2003) to assess the impact of school transitions on factors associated with a turning point in the life course to account for the nested structure of our data, with multiple observations (i.e., Level 1-within person effects) nested within persons (i.e., Level 2-between person effects), who are nested in schools (i.e., Level 3-between school effects). Discontinuous regression models are well-suited for this analysis because they allow for both the examination of immediate changes in the outcome (e.g., peer delinquency, school commitment) that accompany school transitions, as well as ongoing changes in the outcome the longer respondents remained in a particular school. This strategy also allows for the examination of potential interaction effects associated with gang desistance when it occurs at the same time as a school transition. That is, these models can detect whether or not the gang desistance process is particularly impactful when it is accompanied by a change in schools. ${ }^{10}$

\section{School Transitions as a Turning Point for Gang Desistance}

In the qualitative interviews youth were asked to expound upon the various reasons why they began to disengage from their gang. Of the 107 youth who reported desisting from a gang, approximately 59 percent discussed how school transitions impacted their disengagement process. A major theme that emerged centered on the ability of school transitions to facilitate changes in peer groups via either a knifing off of gang ties or a gradual process (see Decker and Lauritsen 2002). The knifing off of gang ties was illustrated through discussions of an abrupt change in the peer group. Curtis, for example, stated, "As we hit new schools we never talked to each other again" and Jasmin echoes, "Yeah...everybody like split up." Other youth discussed a more gradual disengagement process. Harry, for instance, explained how his gang broke apart "I

\footnotetext{
${ }^{10}$ Analyses were conducted in HLM 7.0. Missing data were handled through listwise deletion. The final sample size for all models was 3,233 respondents.
} 
mean, ever since 9th grade when we separated, little by little we just stopped hanging out, we got into high school [and] we hang out with different people now." Similarly, Maria described how her gang maintained contact at first, “....after I moved schools, like, they talked to me for, like, the first month or two and then after that they stopped talking to me."

The process of breaking away from gang peers following a school transition is commonly associated with building new friendships, akin to Sergio's statement “...I met new people and I hang out with different people." Mariah discussed that after her school transition her peers were more prosocial in nature: "I just went to a different high school and I met better, like, other people." While less common than discussions of new peer connections, youth also described their school transition in ways that are consistent with a hook for change. Brandon illustrates this point when asked by the interviewer if his school transition was beneficial:

Yeah definitely...'cause I mean...I was talking to my friend the other day, he's like "Man, if you woulda kept going to [Previous School]" he's like "Who knows where you woulda been right now" and I was like "Yeah that's pretty crazy" I could be, my life could be, you know, [in a] totally different direction, but yeah goin' over to [Current School] and settling down, focusing on school and college.

Still other youth discussed their cognitive decision to change schools, which indicates they began a self-reflection process and, therefore, viewed school transitions as a way to facilitate the gang desistance process. For example, Jeremey reveals that "Yeah, I changed schools. Mostly [to] get away from people at that school." Additionally, Jose discusses the fact that he chose to distance himself from his former gang:

It was just kinda my decision... I stopped hanging out with them kind of towards the end of 10th grade, but then what made it better for me [was] to be, like, just stick completely away from 'em that's when I switched to [Current School] going into Junior year. So like I had like no contact with them I had no reason to be around 'em or anything. 
These narratives illustrate how school transitions can help to facilitate the relationship between gang desistance and correlates of gang membership such as changes in peer groups as well as by providing opportunities for self-reflection, which could lead to changes in self-identity. In the next section, we examine the direct relationship between school transitions and gang status using the quantitative data.

\section{A Quantitative Look at School Transitions and Gang Status}

Before describing our multivariate analyses, we begin by describing the univariate descriptive statistics and bivariate measures of association related to school transitions and gang membership. As seen in table 1, we observed at least one school transition for the majority of our sample (74.3\%), while just over 11 percent of respondents experienced more than one school move. ${ }^{11}$ The majority of these cases $(59.3 \%)$ represent the normative movement of respondents from middle schools to high school. Fifteen percent of the sample experienced a non-normative transition. Results suggest that school transitions are not associated with gang joining, as only $13.2 \%$ of cases of gang joining $(n=38)$ occurred at the time of a normative school transition $($ Chi2 $=.171, \mathrm{df}=1, \mathrm{p}>.05)$, and only $3.5 \%$ of the total number of observations of gang joining $(\mathrm{n}=10)$ occurred during the same wave as a non-normative school transition $(\mathrm{Chi} 2=.012, \mathrm{df}=$ $1, \mathrm{p}>.05)$. There was also no association between being in a gang and school transitions overall $($ Chi2 $=.184, \mathrm{df}=1, \mathrm{p}>.05)$, given roughly $16.9 \%$ of the total number of observations of gang membership occurred at the same wave as a school transition (i.e., 136 of 804). There was also no association between gang membership and school transitions when the type of transition (i.e., normative or non-normative) was accounted for. School transitions were, however, significantly

\footnotetext{
${ }^{11}$ It is important to note that everyone in our sample experienced the normal transition to high school. The 25.7 percent of youth who did not transition in our sample simply did not transition during the times for which we have survey data for them.
} 
and positively associated with observations of gang desistance $($ Chi2 $=21.48, \mathrm{df}=1, \mathrm{p}<.05)$, with $27.2 \%$ of all instances of leaving a gang observed at the same wave of a school transition (i.e., 88 of 324 observed cases ${ }^{12}$ ). With respect to the type of school transition, results suggest that gang desistance was significantly associated with normative school transitions $(\mathrm{Chi} 2=$ 14.42, $\mathrm{df}=1, \mathrm{p}<.05)$, as well as non-normative school transitions $($ Chi2 $=7.67, \mathrm{df}=1, \mathrm{p}<.05)$ at the bivariate level. In sum, school transitions do not appear to be a catalyst for gang joining, but they are associated with gang desistance. ${ }^{13}$

We next move on to our multivariate analyses, where we assess the association between school transitions and changes in gang status using panel fixed effects models. Importantly, these models control for time, which takes into account any systematic change in the probability of gang status transitions over time, as well as all time stable characteristics of respondents. In all, models 1, 2, and 3 examine the probability of joining a gang for the first time (i.e., gang joining), being in a gang regardless of prior gang membership status (i.e., gang membership), or leaving a gang (i.e., gang desistance) at the time of either a normative school transition or a non-normative transition. After controlling for these myriad factors, model 1 suggests that changing schools is unassociated with gang joining. With respect to being in a gang after a school transition, regardless of whether or not they had previously reported being in a gang, model two suggests there is also no association between school transitions and gang membership, regardless of the type of school transition experienced. Finally, with respect to our fixed effects regression analysis for those youth who reported leaving a gang at some point in our study, results suggest that their probability of desisting from gang activity increased as they experienced a normative

\footnotetext{
${ }^{12}$ We did not have valid transition data from one respondent for which we observed gang desistance.

${ }^{13}$ With the exception of the post-test, which was conducted in the spring of the initial school year of data collection, survey data were collected in the fall of each school year.
} 
transition to a new school $(b=.30, p<.05)$, but was unassociated with non-normative school transitions $(b=.16, p>.05)$.

Given the results, which suggest the probability of joining a gang diminishes after a school transition, while the probability of leaving a gang increases systematically, we turn our attention to our second research question: What is the influence of school transitions on correlates of gang membership considered to be consistent with a turning points framework in prior research? The odd numbered models in table 3 provide information on the association between school transitions and time after a school transition on these factors, while controlling for a number of demographic characteristics, including gang membership status as well as the linear time trend. Due to space constraints, however, we limit our tables to only those variables related to our research questions under consideration, although all models control for all of the characteristics described in our measures section, and included in table 2 (full model results available upon request).

With respect to peer group size, results suggest that, on average, the size of a peer group increases slightly across time $(b=.03)$. As youth change schools, the size of their peer group diminishes abruptly $(b=-.15)$, although it does not change significantly more than expected the longer the respondent stays in school. ${ }^{14}$ The impact of school transitions on the proportion of respondents' peers who are prosocial suggests that youth are surrounded by a systematically more prosocial peer group than prior to their school transition $(b=.10)$ and that this proportion increases the longer they remain in that school $(b=.12)$. The proportion of delinquent friends, however, does not change systematically during a school transition, although the longer youth spend in their new school their rate of growth in delinquent peers is slowed $(b=[-.06+.10]=$

\footnotetext{
${ }^{14}$ Calculation of the effect of time in a new school is equal to the sum of the effect of time and time in new school.
} 
$.04)$ relative to the average growth across time $(b=.10)$. Commitment to school increases abruptly $(b=.09)$ as youth transition schools, and then appears to level off the longer youth remain in their new school $(b=[.08=-.09]=-.01)$. Neutralizations for violent behavior diminish during a school transition $(b=-.17)$, as well as the longer youth remain in a new school $(b=-$ $.09)$, effectively canceling out the upward trend in this variable found in the data $(b=[-.09+.07]$ $=-.02$ ). Parental monitoring appears to decrease slightly immediately following a school transition $(b=-.05)$, although it increases thereafter $(b=.04)$. While commitment to deviant peers increased slightly, on average, across time, and school transitions did not produce an immediate impact on these attitudes, the intensity of these attitudes remained stable the longer youth spent in the new school $(b=[-.11+.12]=.01)$. Similarly, while unstructured socializing increased systematically across time, and was not immediately impacted by a school transition, this rate of increase slowed significantly the longer youth remained in a new school $(b=[.11+-$ $.05]=.06)$. From an emotional standpoint, while anticipated guilt for participating in deviant acts diminished across time for the sample, and was not impacted immediately upon transition into a new school, this downward trend was not as steep the longer youth remained in their new school $(b=[-.09+.05]=-.04)$. Anger identity, however, diminished significantly as youth transitioned to a new school $(b=-.10)$ and continued this downward trend the longer they remained in a new school $(b=-.11)$. In sum, current results suggest that school transitions do not produce systematic negative consequences on youth, and actually appear to produce a positive impact on factors associated with crime, deviance, and gang membership. The magnitude of the impact of school transitions on these variables, however, is rather small in absolute terms.

Lastly, the even numbered models in table 3 provide results pertinent to our third research question, which addresses whether changes in gang status that occur at the same time as 
a school transition ${ }^{15}$ produce a differential impact on these associated correlates of gang membership. Given results in table 2, these models focus solely on gang desistance, as there is no evidence that school transitions lead to gang joining in a systematic fashion. With respect to peer group size, while self-reported gang members $(b=1.39)$ and those who desisted from gang membership $(b=.54)$ report significantly larger peer groups than those youths who never reported gang membership, when youth report leaving a gang at the same time they transitioned to a new school, findings indicate that the size of their peer group diminishes to a greater extent than youth who desisted from gang membership but remained in the same school $(b=-.27)$. While school transitions were found to lead to an increase in the proportion of prosocial peers more generally $(b=09)$, the impact was especially pronounced for youth who reported leaving a gang during the transition to a new school $(\mathrm{b}=.20)$. Similarly, while school commitment improved, on average, as youth transitioned to a new school, this effect was stronger for youth who also reported desisting from a gang $(b=.28)$. There was also a significant decline in the acceptance of neutralizations for violence for youth who reported leaving a gang during a school transition $(b=-.20)$. While school transitions did not produce an immediate impact on anticipated guilt for youth more generally, youth who reported leaving a gang at the transition point reported higher levels of guilt $(b=.10)$ than would have been expected had they desisted from gang membership but remained in the same school. Finally, desistance from gang membership during a school transition did not produce systematically different results than gang desistance at other points in time for peer delinquency, parental monitoring, negative peer commitment, unstructured socializing, and anger identity. It should be noted, however, that those

\footnotetext{
${ }^{15}$ Given the relatively small number of non-normative school transitions, and the fact that the effect was in the same direction as normal school transitions in the fixed effects models, we use the overall school transition variable in all models in table 3 .
} 
who reported having left a gang reported lower levels of these variables than was reported by gang involved youth.

\section{Discussion and Conclusion}

Our study expands research on the intersection between gang status and life course criminology by examining the impact of school transitions as a potential facilitator to change gang status. Both qualitative and quantitative studies on gang desistance point toward the utility of life events, such as school moves, in facilitating these processes. Moreover, prior work demonstrates that school transitions (whether normative or otherwise) impact several correlates of gang membership such as academic outcomes, peer relations, extracurricular activities, and individual attributes. The relationship of school transitions to these variables - which are also associated with a turning points framework — suggest that school transitions may provide opportunities for change in gang membership status. Informed by this prior research we pursued three main goals: 1) explore the direct impact of school transitions on gang status; 2) examine the impact of school transitions on correlates of gang membership considered to be consistent with the turning points framework in prior research (Melde and Esbensen 2011, 2014); and 3) examine the interaction between two potential turning points, changes in gang status and school transitions, on changes in these correlates of gang membership. Our findings add to the life course literature as well as research on gang desistance by considering an underexplored event, school transition, as a potential turning point. This research adds another piece to the gang desistance puzzle by identifying the positive impact that school change has on gang desistance and correlates of gang membership [see figure 1]. Interestingly, though, we did not find any evidence to suggest that school mobility facilitated gang joining. 
Results from prior work on motivations for gang desistance have suggested that life events such as changing residences and/or transitioning to a new school can facilitate gang desistance. Both our qualitative and quantitative results confirmed this relationship. Youth who experienced a school transition were significantly more likely to be gang desisters. While this study is the first, at least to our knowledge, to examine the direct impact of school transitions on gang status, it also confirms both qualitative and quantitative research on motivations for gang desistance, which typically find school or residential mobility play a role in this process (Carson and Esbensen 2016; Carson, Peterson, and Esbensen 2013; Decker and Lauritsen 2002; Decker and Pyrooz 2011). Moreover, our qualitative analysis identified some of the underlying processes associated with this relationship. During the in-depth interviews, youth discussed how the transition to a new school changed their associations with their gang peers. The connections were broken gradually in some cases and more abruptly in others, but the school transition allowed youth to build new, oftentimes prosocial, friendships. Consistent with a turning point framework and prior research (Melde and Esbensen 2014), the "knifing off" of gang attachments (i.e., gang desistance) is associated with increases in commitment to school as well as prosocial peers. The quantitative findings presented here indicate that youth who desist from their gang in conjunction with a school transition experience greater increases in their commitment to school and more attachments to prosocial peers.

In addition to examining the impact of school transitions on peer associations, we explored the impact on guilt associated with delinquent acts and neutralizations for violence in order to capture changes in conventional beliefs associated with a severing of gang membership. While themes related to this did not appear in the qualitative analysis, our quantitative results demonstrated that youth who simultaneously disengaged from the gang and changed schools 
reported more feelings of guilt as well as fewer rationalizations for violent behavior than those who desisted without a change in schools. It appears then that the impact of gang desistance on variables associated with the knifing off of gang attachments is amplified in the presence of a school transition.

Neither the qualitative nor quantitative analyses were able to identify changes in other variables consistent with the turning point framework, indicating that school transitions do not amplify the relationship between gang desistance and patterns of supervision (e.g., parental monitoring) and investments in new or old relationships (e.g., negative peer commitment). These results, especially in the quantitative analysis, are not surprising as Melde and Esbensen (2014) found that these variables did not change upon leaving a gang. Our qualitative and quantitative analyses were unable to identify an amplification effect of school transitions on the relationship between gang desistance and unstructured socializing and associations with delinquent peers.

School transitions, however, can act as hooks for change by providing gang youth an opportunity for self-reflection, which was a noticeable theme in the qualitative interviews. In these narratives youth expressed a conscious decision to leave the gang through self-reflection at the time of the school transition and also discussed how they and their goals changed after moving to a new school. This suggests that youth may have already begun to shed the label of gang member and initiated the process of taking on a new role. We attempted to capture these changes in the quantitative analysis by examining changes in anger identity. Results, however, showed no amplification effect of school transitions on the relationship between gang desistance and anger identity. It is unlikely that the null findings indicate that youth have not had time to formulate a change in identity, as there was also no effect for time in the new school. It is 
possible, however, that changes in identity came in other forms not captured in our quantitative data.

Overall, our findings indicate that school transitions have some utility in facilitating gang desistance and for amplifying factors associated with knifing off from the gang. However, the results with regards to identity transformation were not as conclusive. While the qualitative results indicat that school transitions can act as hooks for change, this was not supported by our quantitative analyses. Despite this finding, the results presented here will be helpful to practitioners working in a school setting and indicate that focus should be placed on helping youth who are making school transitions build prosocial attachments. School transitions are an important opportunity for youth, especially gang youth, to get a fresh start and shed the label of gang member. However, given the omnipresence of gangs in many communities, youth will most likely be exposed to gangs in their new school; therefore, it is especially important to use this opportunity to build ties with nondelinquent peers and to work to increase their involvement in school and commitment to their grades and their future.

Prior research also indicated that school transitions could increase the likelihood of gang joining as a way to quickly garner social capital, which the gang can provide (Alleyne and Wood 2010; McGloin and Collins 2015; Woo et al. 2015). Moreover, youth who move to a new school are at risk for victimization (Carson, Esbensen, and Taylor 2013), which may result in joining a gang for the perceived protection they can provide. We did not find support for these propositions. This null finding may be attributable to the fact that joining a gang simultaneous with transitioning schools is an extremely rare event in our data. In the over 20,000 observations in the sample, we only observed 48 instances where youth reported joining a gang at the same time that s/he experienced a school transition. The low probability of simultaneously 
experiencing gang joining and school transition is consistent with prior literature that finds that school mobility is not predictive of association with delinquent peers (Siennick, Widdowson, and Ragan 2016). However, we are hesitant to completely reject this hypothesis and suggest that future research should continue to explore this link with gang or nongang high-risk youth, as some prior research suggests that school transitions are particularly difficult for a small group of students who were previously considered high-risk (Roderick, 1993). Additionally, future research should examine the impact of moving to schools with higher levels of disorder on gang joining. Students report higher levels of fear and victimization in schools with high levels of disorder (Gottfredson 2001; Randa and Wilcox 2010; Schreck and Miller 2003); therefore, a lack of social capital may be especially impactful for youth transitioning to these schools.

Additionally, it is important to note that our findings with regards to gang joining could be seen as being inconsistent with observations from Vigil (1993). He found evidence of an increase in gang joining during the early school transition from elementary to middle school, while we find the opposite for later school transitions. One possible explanation for the dissident findings is that later transitions more closely approximate the time in a youth's life course when they are beginning to transition out of the gang (Craig et al. 2002; Esbensen and Huizinga 1993; Huff 1996, 1998; Pyrooz 2014). Fortunately, we were able to control for the relationship between age and gang status in our analysis, which helps to isolate the role of school transitions from age and grade-level effects, unlike Vigil (1993) and others who have examined the age and grade-level correlates of the gang career.

Our discussion has focused on the impact of school transitions on gang status as well as its ability to amplify the relationship between gang desistance and factors associated with the turning point framework. Our results, however, are also able to inform the school transitions 
literature through examination of the direct impact of school transitions on academic outcomes, peer relationships, extracurricular activities, and individual attributes. Our results demonstrat that school transitions have an immediate positive impact on many of these measures including commitment to school, improved associations with prosocial peers, decreased rationalizations for violent behavior, and reduced anger identity. Additionally, as youth spent time in their new school they continued to see improvement in these variables and experienced a lagged reduction in delinquent friends, commitment to delinquent youth, and a decrease in unstructured socializing. The findings are mostly consistent with prior literature (Barber and Olsen 2004; Kinney 1993; Roeser, Eccles, and Freedman-Doan 1999; Weiss and Bearman 2007) and indicate that breaking away from peers and the subsequent loss of social capital can act as a turning point for youth, allowing them to build more prosocial bonds to peers and school as well as help transform their self-identity.

This work adds to the understanding of the impact of school transitions on gang status and correlates of gang membership, but also suffers from some limitations. The nature of these data limits the ability to generalize to the entire population. While the G.R.E.A.T. data offer a sample that is geographically broad, it is not nationally representative of the United States. Additionally, the reliance on a school-based sample to study gang membership limits our ability to examine the most highly delinquent members of the gang as well as older gang youth. However, the focus on a young population is important as younger offenders are more likely to occupy groups, are less entrenched in their delinquent ways (Pyrooz and Decker 2011), and are, therefore, more susceptible to change. 


\section{References}

Alleyne, E., and J. L. Wood. 2010. "Gang involvement: Psychological and behavioral characteristics of gang members, peripheral youth, and nongang youth." Aggressive Behavior 36:423-436.

Allison, P. D. 2009. Fixed Effects Regression Models. Thousand Oaks: Sage.

Barber, B. K., and J. A. Olsen. 2004. "Assessing the transitions to middle and high school." Journal of Adolescent Research 19:3-30.

Benner, A. D. 2011. "The transition to high school: Current knowledge, future directions." Educational Psychology Review 23:299-328.

Benner, A. D., and S. Graham. 2009. "The transition to high school as a developmental process among multiethnic urban youth." Child Development 80:356-376.

Blyth, D. A., R. G. Simmons, and S. Carlton-Ford. 1983. "The adjustment of early adolescents to school transition." Journal of Early Adolescence 3:105-120.

Brunson, R. K., and J. Miller. 2009. "Schools, neighborhoods, and adolescent conflicts: A situational examiniation of reciprocal dynamics." Justice Quarterly 26:183-210.

Carson, D. C., and F.-A. Esbensen. 2016. "Motivations for leaving: A qualitative comparison of leaving processes across gang definition." In Gang Transitions and Transformations in an International Context, edited by C.L. Maxson and F.-A. Esbensen, 139-155. New York: Springer.

Carson, D. C., F.-A. Esbensen, and T. J. Taylor. 2013. "A longitudinal analysis of the relationship between school victimization and student mobility." Youth Violence and Juvenile Justice 11:275-294.

Carson, D. C., D. Peterson, and F.-A. Esbensen. 2013. "Youth gang desistance: An examination of the effect of different operational definitions of desistance on the motivations, methods, and consequences associated with leaving the gang." Criminal Justice Review 38:510-534.

Charmaz, K. 2006. Constructing Grounded Theory: A Practical Guide Through Qualitative Analysis. Thousand Oaks: Sage.

Coleman, J. S. 1990. Foundations of Social Theory. Cambridge, MA: Belknap Press of Harvard University Press.

Craig, W. M., F. Vitaro, C. Gagnon, and R. E. Tremblay. 2002. "The road to gang membership: Characteristics of male gang and nongang members from ages 10 to 14." Social Development 11:53-68.

Decker, S. H. 1996. "Collective and normative features of gang violence." Justice Quarterly 13:245-264.

Decker, S. H., and G. D. Curry. 2000. "Addressing key features of gang membership: Measuring the involvement of young members." Journal of Criminal Justice 28:473-482.

Decker, S. H., and J. L. Lauritsen. 2002. "Leaving the gang." In Gangs in America, edited by C.R. Huff, 51-67. Thousand Oaks, CA: Sage Publications.

Decker, S. H., and D. C. Pyrooz. 2011. Leaving the gang: Logging off and moving on. Council on Foreign Relations.

Decker, S. H., D. C. Pyrooz, and R. K. Moule Jr. 2014. "Disengagement from gangs as role transitions." Journal of Research on Adolescence 24:268-283. 
Decker, S. H., D. C. Pyrooz, G. Sweeten, and R. K. Moule Jr. 2014. "Validating self-nomination in gang research: Assessing differences in gang embeddedness across non-, current, and former gang members." Journal of Quantitative Criminology 30:577-598.

Decker, S. H., and B. Van Winkle. 1996. Life in the Gang: Family, Friends, and Violence. New York: Cambridge University Press.

Eccles, J. S., S. Lord, and C. Midgley. 1991. "What are we doing to early adolescents? The impact of educational contexts on early adolescents." American Journal of Education 99:521-542.

Eccles, J. S., and C. Midgley. 1988. "Stage/environment fit: Developmentally appropriate classrooms for early adolescents." In Research on Motivation in Education, vol. 3, edited by R.E. Ames and C. Ames, 136-186. New York: Academic Press.

Esbensen, F.-A., and D. Huizinga. 1993. "Gangs, drugs, and delinquency in a survey of urban youth." Criminology 31:565-589.

Esbensen, F.-A., C. Melde, T. J. Taylor, and D. Peterson. 2008. "Active parental consent in school-based research: How much is enough and how do we get it?" Evaluation Review 32:335-362.

Esbensen, F.-A., D. W. Osgood, D. Peterson, T. J. Taylor, and D. C. Carson. 2013. "Short- and long-term outcome results from a multisite evaluation of the G.R.E.A.T. program." Criminology \& Public Policy 12:375-411.

Esbensen, F.-A., D. W. Osgood, T. J. Taylor, D. Peterson, and A. Freng. 2001. "How great is G.R.E.A.T.?: Results from a quasi-experimental design." Criminology \& Public Policy 1:87-118.

Esbensen, F.-A., and D. Peterson Lynskey. 2001. "Young gang members in a school survey." In The Eurogang Paradox: Street Gangs and Youth Groups in the U.S. and Europe, edited by M.W. Klein, H.-J. Kerner, C.L. Maxson and E.G.M. Weitekamp, 93-114. Dordrecht: Kluwer Academic Publishers.

Esbensen, F.-A., and L.T. Winfree, Jr.. 2013. "Motivations for gang joining: Does context matter?" In Festscrift for Hans Kerner, edited by K. Boers, T. Feltes, J. Kinzig, L.W. Sherman and F. Streng. Tuebingen, Germany: Mohr Publishing.

Esbensen, F.-A., L.T. Winfree, Jr., N. He, and T. J. Taylor. 2001. "Youth gangs and definitional issues: When is a gang a gang and why does it matter?" Crime \& Delinquency 47:105130.

Fuligni, A. J., J. S. Eccles, B. L. Barber, and P. Clements. 2001. "Early adolescent peer orientation and adjustment during high school." Developmental Psychology 37:28-36.

Gasper, J., S. DeLuca, and A. Estacion. 2010. "Coming and going: Explaining the effects of residential and school mobility on adolescent delinquency." Social Science Research 39:459-476.

Giordano, P. C., R. D. Schroeder, and S. A. Cernkovich. 2007. "Emotions and crime over the life course: A Neo-Median perspective on criminal continuity and change." American Journal of Sociology 112:1603-1661.

Glaser, B. G., and A. Strauss. 1967. The Discovery of Grounded Theory. New York: Aldine.

Gottfredson, D. C. 2001. Schools and Delinquency. New York, NY: Cambridge University Press.

Gottfredson, G. D., and D. C. Gottfredson. 2001. Gang Problems and Gang Programs in a National Sample of Schools. Ellicot City, MD: Gottfredson Associates. 
Graber, J. A., and J. Brooks-Dunn. 1996. "Transitions and turning points: Navigating the passage from childhood through adolescence." Developmental Psychology 32:768-776.

Grasmick, H. G., C. R. Tittle, R. J. Bursik, and B. J. Arneklev. 1993. "Testing the core empirical implications of Gottfredson and Hirschi's General Theory of Crime." Journal of Research in Crime and Delinquency 30:5-29.

Hagan, J., R. MacMillan, and B. Wheaton. 1996. "New kid in town: Social capital and the life course effects of family migration on children." American Sociological Review 61:368385.

Huff, C. R. 1996. "The criminal behavior of gang members and non-gang at-risk youth." In Gangs in America (2nd edition), edited by C.R. Huff, 75-102. Thousand Oaks: Sage.

Huff, C. R. 1998. Comparing the criminal behavior of youth gangs and at-risk youths. Washington, D.C.: National Institute of Justice: Research in Brief.

Isakson, K., and P. Jarvis. 1999. "The adjustment of adolescents during the transition into high school: A short-term longitudinal study." Journal of Youth and Adolescence 28:1-26.

Kinney, D. A. 1993. "From nerds to normals: The recovery of identity among adoelscents from middle school to high school." Sociology of Education 66:21-40.

Langenkamp, A. G. 2016. "Effects of school mobility on adolescent social ties and academic adjustment." Youth \& Society 48:810-833.

Leventhal, T., and J. Brooks-Gunn. 2004. "A randomized study of neighborhood effects on lowincome children's educational outcomes." Developmental Psychology 40:488-507.

Ludwig, J., H. F. Ladd, and G. J. Duncan. 2001. "Urban poverty and and educational outcomes." In Brookings-Wharton Papers on Urban Affairs, edited by W. Gale and J. Rothenberg Pack. Washington, D.C.: Brookings Institution.

McGloin, J. M., and M. E. Collins. 2015. "Micro-level processes of the gang." In The Handbook of Gangs, edited by S.H. Decker and D.C. Pyrooz, 276-293. New York: Wiley.

Meeus, W. 2011. "The study of adolescent identity formation 2000-2010: A review of longitudinal research." Journal of research on Adolescence 2:75-94.

Melde, C., and F.-A. Esbensen. 2011. "Gang membership as a turning point in the life course." Criminology 49:513-552.

Melde, C., and F.-A. Esbensen. 2014. "The relative impact of gang status transitions: Identifying the mechanisms of change in delinquency." Journal of Research in Crime and Delinquency 51:349-376.

Melde, C., T. J. Taylor, and F.-A. Esbensen. 2009. "'I got your back': An examination of the protective function of gang membership in adolescence." Criminology 47:565-594.

Moule Jr., R. K., S. H. Decker, and D. C. Pyrooz. 2013. "Social capital, the life-course, and gangs." In Handbook of Life-Course Criminology: Emerging Trends and Directions for Future Research, edited by C. Gibson and M.D. Krohn, 143-158. New York: Springer.

Pedersen, M. L., and J. M. Lindstad. 2012. "The Danish gang-joining project: Methodological issues and preliminary results." In Youth Gangs in International Perspective: Results from the Eurogang Program of Research, edited by F.-A. Esbensen and C.L. Maxson, 239-250. New York: Springer.

Pribesh, S., and D. B. Downey. 1999. "Why are residental and school moves associated with poor school performance?" Demography 36:521-534.

Pyrooz, D. C. 2014. "“From your first cigarette to your last dyin' day": The patterning of gang membership in the life-course." Journal of Quantitative Criminology 30:349-372. 
Pyrooz, D. C., and S. H. Decker. 2011. "Motives and methods for leaving the gang:

Understanding the process of gang desistance." Journal of Criminal Justice 39:417-425.

Pyrooz, D. C., S. H. Decker, and V. J. Webb. 2014. "The ties that bind: Desistance from gangs." Crime \& Delinquency 60:491-516.

Pyrooz, D. C., and J. A. Densley. 2016. "Selection into street gangs: Signaling theory, gang membership, and criminal offending." Journal of Research in Crime and Delinquency 53:447-481.

Pyrooz, D. C., A. M. Fox, and S. H. Decker. 2010. "Racial and ethnic heterogeneity, economic disadvantage, and gangs: A macro-level study of gang membership in urban America." Justice Quarterly 27:867-892.

Randa, R., and P. Wilcox. 2010. "School disorder, victimization, and general v. place-specific student avoidance." Journal of Criminal Justice 38:854-861.

Roeser, R. W., J. S. Eccles, and C. Freedman-Doan. 1999. "Academic functioning and mental health in adolescence: Patterns, progressions, and routes from childhood." Journal of Adolescent Research 14:135-174.

Rumberger, R. W., and K. A. Larson. 1998. "Student mobility and the increased risk of high school dropout." American Journal of Education 107:1-35.

Rutter, M. 1996. "Transitions and turning points in developmental psychology: As applied to the age span between childhood and mid-adulthood." Internaltional Journal of Behavioral Development 19:603-626.

Sampson, R. J., and J. H. Laub. 2005. "A life-course view of the development of crime." ANNALS of the American Academy of Political and Social Sciences 602:12-45.

Schreck, C. J., and J. M. Miller. 2003. "Sources of fear of crime at school: What is the relative contribution of disorder, individual characteristics, and school security?" Journal of School Violence 2:57-79.

Seidman, E., L. Allen, J. L. Aber, C. Mitchell, and J. Feinman. 1994. "The impact of school transitions in early adolescence on the self-system and perceived socail context of poor urban youth." Child Development 65:507-522.

Siennick, S. E., A. O. Widdowson, and D. T. Ragan. 2016. "New students' peer integration and exposure to deviant peers: Spurious effects of school moves?" Journal of Early Adolescence. doi: DOI: 10.1177/0272431616659563.

Singer, J. D., and J. B. Willett. 2003. Applied Longitudinal Data Analysis. New York: Oxford University Press.

Smetana, J. G., N. Campione-Barr, and A. Metzger. 2006. "Adolescent Development in Interpersonal and Societal Contects." Annual Review of Psychology 57:255-284.

South, S. J., and D. L. Haynie. 2004. "Friendship networks of mobile adolescents." Social Forces 83:315-350.

Sykes, G. M., and D. Matza. 1957. "Techniques of neutralization: A theory of delinquency." American Sociological Review 22:664-670.

Symonds, J. E., and M. Galton. 2014. "Moving to the next school at age 10-14 years: An international review of psychological development at school transition." Review of Education 2:1-27.

Taylor, T. J., A. Freng, F.-A. Esbensen, and D. Peterson. 2008. "Youth gang membership and serious violent victimization: The importance of lifestyles and routine activities." Journal of Interpersonal Violence 23:1441-1464. 
Taylor, T. J., D. Peterson, F.-A. Esbensen, and A. Freng. 2007. "Gang membership as a risk factor for adolescent violent victimization." Journal of Research in Crime and Delinquency 44:351-380.

Thornberry, T. P., M. D. Krohn, A. J. Lizotte, C. A. Smith, and K. Tobin. 2003. Gangs and Delinquency in Developmental Perspective. New York: Cambridge.

Vigil, J. D. 1993. "The established gang." In Gangs: The Origins and Impact of Contemporary Youth Gangs in the United States, edited by S. Cummings and D.J. Monti, 95-112. Albany, NY: State University of New York Press.

Warr, M. 1998. "Life-course transitions and desistance from crime." Criminology 26:183-216.

Warr, M. 2002. Companions in Crime: The Social Aspects of Criminal Conduct. Cambridge: Cambridge University Press.

Weerman, F. M. 2012. "Are correlates and effects of gang membership sex-specific? Troublesome youth groups and delinquency in Dutch girls." In Youth Gangs in International Perspective: Results from the Eurogang Program of Research, edited by F.-A. Esbensen and C.L. Maxson, 271-287. New York: Springer.

Weiss, C. C., and P. S. Bearman. 2007. "Fresh starts: Reinvestigating the effects of the transition to high school on student outcomes." American Journal of Education 113:395-421.

Weller, S. 2007. "'Sticking with your mates?' Children's friendship trajectories during the transition from primary to secondary school." Children \& Society 21:339-351.

Woo, D., H. Giles, M. A. Hogg, and L. Goldman. 2015. "Social pyschology of gangs: An intergroup communication perspective." In The Handbook of Gangs, edited by S.H. Decker and D.C. Pyrooz, 136-156. New York: Wiley. 
Table 1: Descriptive Statistics

\begin{tabular}{|c|c|c|c|c|}
\hline Variables & $\mathrm{n}$ & percent & mean & s.d. \\
\hline School Level & $(n=31)$ & & & \\
\hline$\%$ Free and Reduced Lunch & & & $0.64^{1}$ & 0.23 \\
\hline Person Level & $(n=3,820)$ & & & \\
\hline White & 1,041 & $27.3 \%$ & & \\
\hline Black & 687 & $18.0 \%$ & & \\
\hline Hispanic & 1,517 & $39.7 \%$ & & \\
\hline Other & 575 & $15.1 \%$ & & \\
\hline Age & & & 11.47 & 0.71 \\
\hline $\mathrm{Age}^{2}$ & & & 132.13 & 16.73 \\
\hline Male & 1,839 & $48.2 \%$ & & \\
\hline Ever Gang & 512 & $13.5 \%$ & & \\
\hline \multicolumn{5}{|l|}{ School Transitions } \\
\hline 0 school transitions & 983 & $25.7 \%$ & & \\
\hline 1 school transition & 2,408 & $63.0 \%$ & & \\
\hline 2 school transitions & 374 & $9.8 \%$ & & \\
\hline 3 school transitions & 53 & $1.4 \%$ & & \\
\hline 4 school transitions & 2 & $.1 \%$ & & \\
\hline Overall School Transition & 2,837 & $74.30 \%$ & & \\
\hline $\begin{array}{l}\text { Normative School Transition } \\
\text { Non-normative School }\end{array}$ & 2,264 & $59.3 \%$ & & \\
\hline Transition & 573 & $15.0 \%$ & & \\
\hline Within Person/Across Time & $(n=20,340)$ & & & \\
\hline Peer Group Size & & & 2.84 & 1.48 \\
\hline Prosocial Peers & & & 3.43 & 0.95 \\
\hline Peer Delinquency & & & 1.48 & 0.67 \\
\hline School Commitment & & & 3.72 & 0.74 \\
\hline Violence Neutralization & & & 3.40 & 1.17 \\
\hline Parental Monitoring & & & 4.07 & 0.76 \\
\hline Negative Peer Commit. & & & 1.93 & 1.00 \\
\hline Unstructured Socializing & & & 1.35 & 0.93 \\
\hline Guilt & & & 2.48 & 0.61 \\
\hline Anger Identity & & & 3.03 & 0.99 \\
\hline
\end{tabular}

${ }^{1}$ The range in percent free and reduced lunch is from a minimum of 23 percent to a maximum of 96 percent of students.

${ }^{2}$ Age reflects age at wave one. Age and age squared were based on age centered at 12 in all regression models. The range in ages of youth across the survey period was from 9 to 18 years, although roughly $90 \%$ of youth were 11 or 12 at baseline and thus

15 or 16 at the final wave of data collection. 
Table 2: The Effect of School Transitions on Gang Member Status

Model 1

Gang Joining ${ }^{1}$

(obs. $=1,468$ )

$(\mathrm{n}=288)$

Time

Normative School Transition

Non-normative Transition

Log Likelihood

Wald $\mathrm{Chi}^{2}(d f)$
Model 2

Gang Membership ${ }^{1}$

(obs. $=2,302$ )

$(n=462)$

$-0.13$

0.08

$-0.21$

$-819.07$

$11.44 *(3)$
Model 3

Gang Desistance

(obs. $=1,636$ )

$(n=305)$

$0.17 \quad 0.04 *$

$0.30 \quad 0.15 *$

$0.16 \quad 0.33$

$-507.59$

$29.97 *(3)$

$* p<.05 ;$ obs. $=$ total number of observations; $\mathrm{n}=$ total number of respondents note: All models are based upon panel fixed effects logit models using Stata 14.0 (i.e. xtlogit).

Standard errors were produced using bootstrap methods (100 replications), with bias corrected and accelerated confidence intervals, and the seed was set at 100 for replication purposes. 
Table 3: The Effect of School Transitions on Factors Associated with a Turning Point

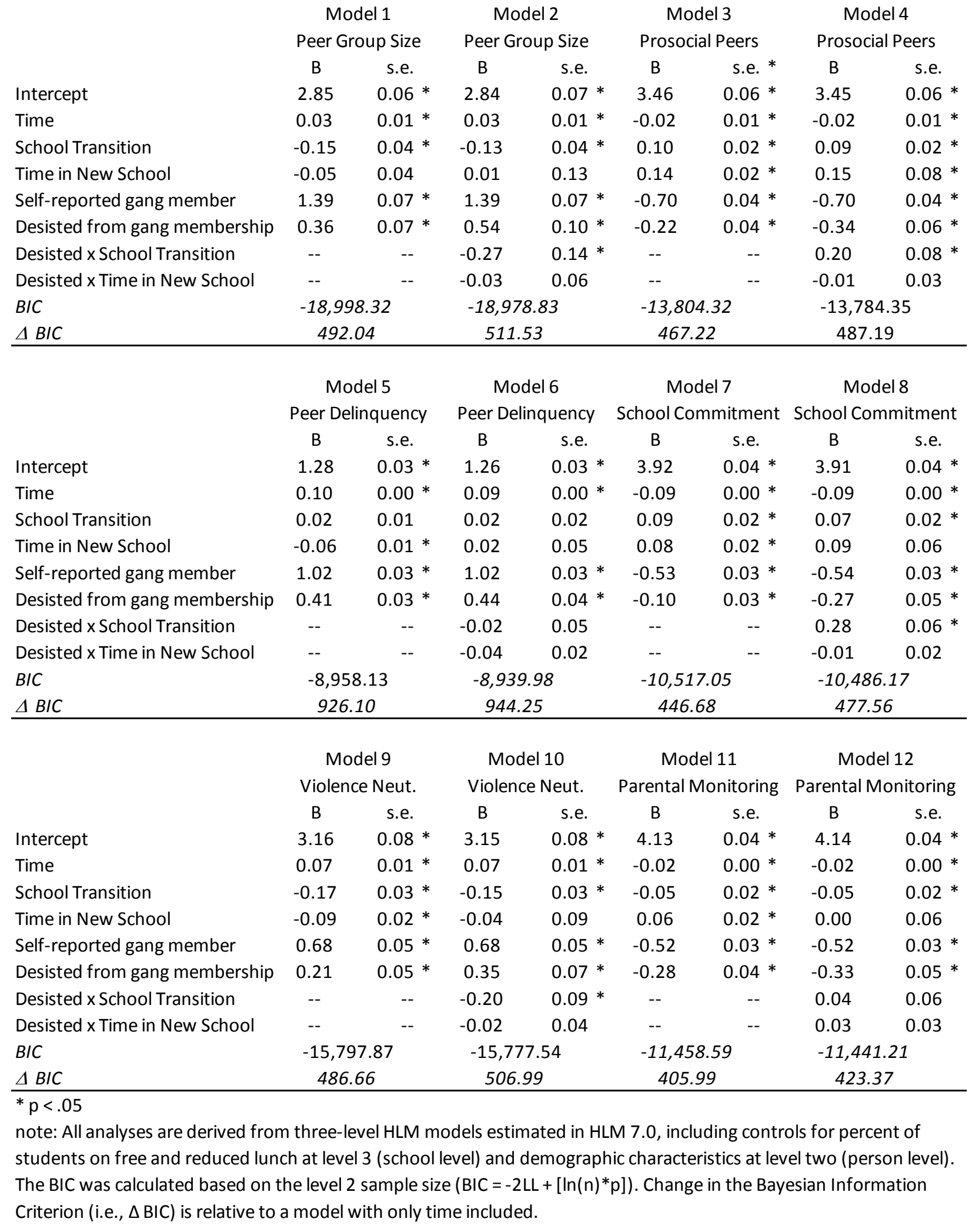


Table 3 (continued) : The Effect of School Transitions on Factors Associated with a Turning Point

\begin{tabular}{|c|c|c|c|c|c|c|c|c|}
\hline & \multicolumn{2}{|c|}{ Model 13} & \multicolumn{2}{|c|}{ Model 14} & \multicolumn{2}{|c|}{$\begin{array}{c}\text { Model } 15 \\
\text { Unstructured }\end{array}$} & \multicolumn{2}{|c|}{$\begin{array}{c}\text { Model } 16 \\
\text { Unstructured } \\
\text { Socializing }\end{array}$} \\
\hline & B & s.e. & B & s.e. & B & s.e. & B & s.e. \\
\hline Intercept & 1.65 & $0.05 *$ & 1.63 & $0.05 *$ & 0.02 & 0.04 & 0.01 & 0.04 \\
\hline Time & 0.12 & $0.01 *$ & 0.12 & $0.01 *$ & 0.11 & $0.01 *$ & 0.11 & $0.01 *$ \\
\hline School Transition & -0.03 & 0.02 & -0.02 & 0.02 & -0.01 & 0.02 & 0.00 & 0.02 \\
\hline Time in New School & -0.11 & $0.02 *$ & 0.04 & 0.08 & -0.05 & $0.02 *$ & 0.02 & 0.06 \\
\hline Self-reported gang member & 0.94 & $0.05 *$ & 0.94 & $0.05 *$ & 0.46 & $0.03 *$ & 0.46 & $0.03 *$ \\
\hline Desisted from gang membership & 0.36 & $0.05 *$ & 0.48 & $0.07 *$ & 0.19 & $0.04 *$ & 0.26 & $0.05 *$ \\
\hline Desisted x School Transition & -- & -- & -0.12 & 0.08 & -- & -- & -0.08 & 0.06 \\
\hline Desisted x Time in New School & -- & -- & -0.07 & 0.04 & -- & -- & -0.03 & 0.03 \\
\hline$B I C$ & \multicolumn{2}{|c|}{$-14,713.85$} & \multicolumn{2}{|c|}{$-14,692.50$} & \multicolumn{2}{|c|}{$-11,712.44$} & \multicolumn{2}{|c|}{$-11,694.30$} \\
\hline \multirow[t]{4}{*}{$\triangle B I C$} & \multicolumn{2}{|c|}{514.05} & \multicolumn{2}{|c|}{535.40} & \multicolumn{2}{|c|}{304.28} & \multicolumn{2}{|c|}{322.42} \\
\hline & \multicolumn{2}{|c|}{ Model 17} & \multicolumn{2}{|c|}{ Model 18} & \multicolumn{2}{|c|}{ Model 19} & \multicolumn{2}{|c|}{ Model 20} \\
\hline & \multicolumn{2}{|c|}{ Guilt } & \multicolumn{2}{|c|}{ Guilt } & \multicolumn{2}{|c|}{ Anger Identity } & \multicolumn{2}{|c|}{ Anger Identity } \\
\hline & B & s.e. & B & s.e. & B & s.e. & B & s.e. \\
\hline Intercept & 2.69 & $0.03 *$ & 2.69 & $0.03 *$ & 3.07 & $0.06 *$ & 3.06 & $0.06 *$ \\
\hline Time & -0.09 & $0.00 *$ & -0.09 & $0.00 *$ & -0.02 & $0.01 *$ & -0.02 & $0.01 *$ \\
\hline School Transition & 0.01 & 0.01 & 0.00 & 0.01 & -0.10 & $0.02 *$ & -0.09 & $0.02 *$ \\
\hline Time in New School & 0.05 & $0.01 *$ & 0.00 & 0.05 & -0.09 & $0.02 *$ & -0.02 & 0.08 \\
\hline Self-reported gang member & -0.54 & $0.03 *$ & -0.54 & $0.03 *$ & 0.49 & $0.04 *$ & 0.49 & $0.04 *$ \\
\hline Desisted from gang membership & -0.35 & $0.03 *$ & -0.43 & $0.04 *$ & 0.32 & $0.05 *$ & 0.40 & $0.06 *$ \\
\hline Desisted x School Transition & -- & -- & 0.10 & $0.05 *$ & -- & -- & -0.10 & 0.08 \\
\hline Desisted x Time in New School & -- & -- & 0.02 & 0.02 & -- & -- & -0.03 & 0.03 \\
\hline$B I C$ & \multicolumn{2}{|c|}{-8402.63} & \multicolumn{2}{|c|}{-8381.68} & \multicolumn{2}{|c|}{-13974.75} & \multicolumn{2}{|c|}{-13956.39} \\
\hline$\triangle B I C$ & \multicolumn{2}{|c|}{474.75} & \multicolumn{2}{|c|}{495.70} & \multicolumn{2}{|c|}{319.14} & \multicolumn{2}{|c|}{337.50} \\
\hline
\end{tabular}

$* \mathrm{p}<.05$

note: All analyses are derived from three-level HLM models estimated in HLM 7.0, including controls for percent of students on free and reduced lunch at level 3 (school level) and demographic characteristics at level two (person level). The BIC was calculated based on the level 2 sample size $\left(B I C=-2 L L+\left[\ln (n)^{*} p\right]\right)$. Change in the Bayesian Information Criterion (i.e., $\triangle \mathrm{BIC}$ ) is relative to a model with only time included. 
Figure 1: Operationalizing a Turning Point

\section{Factors Associated with a Turning Point}

(1) new situations that "knife off" the past from the present

(2) new situations that provide both supervision and monitoring as well as new opportunities of social support and growth

(3) new situations that change and structure routine activities

(4) new situations that provide the opportunity for identity transformation

note: The factors associated with a turning point were drawn directly from Sampson and Laub (2005: 17-18). The measures are not necessarily mutually exclusive across factors, but were assigned above for illustrative purposes only. For example, peer

delinquency could also be an indicator of factor 2, and parental monitoring is also associated with factor 3. The hypothesized direction of the effects, however, is consistent no matter where they are placed.
Measures

Prosocial Peers

School Commitment

Guilt

Violence Neutralizations

Gang Membership

Parental Monitoring

Negative Peer

Commitment

Unstructured Socializing

Peer Delinquency

Anger Identity
School Transition

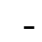

$+$

$+/-$

$+$

$+$

$+$

Hypothesized Direction of Impact 